\section{Controlador de élite curado del virus de hepatitis $C$ tras 14 semanas de triple terapia basada en telaprevir}

\section{Elite controller cured of hepatitis $C$ virus after 14 weeks of telaprevir-based triple therapy}

\section{Sr. Editor}

En la presente carta describimos el primer caso de un paciente controlador de élite del virus de la inmunodeficiencia humana (VIH) que alcanzó una respuesta viral sostenida (RVS) para su infección crónica por el virus de la hepatitis C (VHC), tras 14 semanas de terapia triple basada en telaprevir.

Se trata de un varón de 41 años diagnosticado hace cuatro años de una hepatitis $\mathrm{C}$ crónica genotipo 1a y una infección por VIH estadio A1. El paciente nunca recibió tratamiento antirretroviral, pese a lo cual, la carga viral (CV) de VIH permaneció por debajo del límite de cuantificación, definido como un controlador de élite. Como otros antecedentes de interés, el paciente era usuario de drogas intravenosas hasta hace 10 años y obesidad. Además, se le había diagnosticado una fibrosis hepática grado $\mathrm{F} 2$ según la escala Metavir por Fibroscan ${ }^{\circledR}$ tres años atrás.

Antes de iniciar tratamiento, tenía una $\mathrm{CV}$ para $\mathrm{VHC}$ de $432.000 \mathrm{UI} / \mathrm{ml}(5,63 \mathrm{log})$ y de $\mathrm{VIH}<20$ copias $/ \mathrm{mL}, \mathrm{CD} 4$ de 770 cél $/ \mathrm{mm}^{3}$ (36\%), ALT $52 \mathrm{UI} / \mathrm{L}$, y un polimorfismo del gen IL28B CC. En junio de 2014, tras ampliarse los criterios de utilización de boceprevir y telaprevir establecidos por la Agencia Española del Medicamento y Productos Sanitarios a pacientes F2, el paciente inició tratamiento con telaprevir $2.250 \mathrm{mg} /$ día (tres comprimidos cada $12 \mathrm{~h}$ ) durante las primeras 12 semanas, peg-interferón alfa 2a $180 \mu \mathrm{g}$ a la semana y ribavirina $1.200 \mathrm{mg}$ /día (tres comprimidos cada $12 \mathrm{~h}$ ) durante un total de 24 ó 48 semanas, según respuesta. Tras 14 semanas de tratamiento se debió suspender éste último debido a la aparición de un rash cutáneo e intolerancia digestiva.

Durante el tratamiento, la CV para VIH del paciente permaneció no cuantificable, pese a continuar el paciente sin tratamiento antirretroviral, disminuyendo el número de CD4 a 492 (37\%), 417 (43\%) y 404 cél $/ \mathrm{mm}^{3}$ (43\%) en la semana 4,8 y 12 , aunque manteniendo su porcentaje. La CV para VHC permaneció indetectable desde la segunda semana de tratamiento, manteniéndose así hasta 24 semanas después de la finalización de éste, alcanzando una RVS.

Aunque existen referencias sobre casos de VHC curados en pacientes co-infectados, tras 24 semanas de triple terapia basada en telaprevir ${ }^{2}$, éste es el primer caso en el que un paciente co-infectado alcanza RVS tras solamente 14 semanas de tratamiento. Diversos estudios muestran como los controladores de élite presentan una mayor capacidad para controlar la infección por VHC tanto por aclarar la enfermedad de forma espontánea $a^{3-5}$, como por presentar niveles de replicación más bajos ${ }^{5}$, y aunque no se conoce el mecanismo exacto por el que esto ocurre, estos datos apoyan la idea de la existencia de mecanismos comunes involucrados en la defensa contra estas dos infecciones, como es la presencia del HLA B57, variante del HLA detectada con mayor frecuencia en los controladores de élite ${ }^{6}, \mathrm{y}$ cuya presencia se confirmó en nuestro paciente.

Dado que existen escasas referencias en la literatura especializada sobre el tratamiento del VHC en controladores de élite co-infectados, se desconoce si estos resultados pueden ser extrapolables a otros pacientes con similares características. En este sentido, y tras los resultados obtenidos en nuestro caso, podría plantearse variar el esquema de tratamiento para este grupo de pacientes.

\section{Referencias bibliográficas}

1.- Bedossa P, Poynard T. An algorithm for the grading of activity in chronic hepatitis C. The METAVIR Cooperative Study Group. Hepatology 1996, 24: 289-93.

2.- Cachay E R. Hepatitis C cure after 6 months of telaprevirbased therapy in an HIV-infected man. Clin Infect Dis. 2013; 56: $163-4$

3.- Seaberg E C, Thio C L. A closer look at hepatitis C clearance in HIV controllers. AIDS 2014; 28: 1242-3.

4.- Sajadi M M, Shakeri N, Talwani R, Redfield R R. Hepatitis C infection in HIV-1 natural viral suppressors. AIDS 2010; 24: 1689-95.

5.- Ruiz-Mateos E, Machmach K, Romero-Sánchez MC, Ferrando-Martínez S, Viciana P, Del Val M, et al. Hepatitis C virus replication in Caucasian HIV controllers. J Viral Hepat 2011; 18: e350-7.

6.- Kosmrlj A, Read E L, Qi Y, Allen T M, Altfeld M, Deeks S $\mathrm{G}$, et al. Effects of thymic selection of the T-cell repertoire on HLA class I-associated control of HIV infection. Nature 2010; 465: 350-4

Diego Pérez, Marta Suárez Servicio de Farmacia. Hospital Meixoeiro. EOXI Vigo Sandra Suárez Servicio de Hematología. Hospital Meixoeiro. EOXI Vigo.

Luis E. Morano

Unidad de Patologías Infecciosas. Hospital Meixoeiro. EOXI Vigo.

Correspondencia a: Diego Pérez Parente di_parente@hotmail.com 